\title{
Searching for the Culprit: Metastases from a Cancer of Unknown Primary
}

\author{
Rita Dorantes-Heredia ${ }^{a} \quad$ Daniel Motola-Kuba ${ }^{b}$ Jose Manuel \\ Ruiz-Morales $^{b} \quad$ Wallace Rafael A. Muñoz-Castañeda ${ }^{c}$ Carolina \\ Vega-Ochoa $^{d}$ Roberto De la Peñab
}

${ }^{a}$ Anatomic Pathology Research Unit, Médica Sur Hospital and Clinical Foundation, Mexico City, Mexico; bOncology Research Unit, Médica Sur Hospital and Clinical Foundation, Mexico City, Mexico; 'Internal Medicine Research Unit, Médica Sur Hospital and Clinical Foundation, Mexico City, Mexico; dFacultad de Medicina, Universidad Nacional Autónoma de México, Mexico City, Mexico

\section{Keywords}

Cancer of unknown primary · Metastasis · Breast cancer

\begin{abstract}
We report a case of metastases from a cancer of unknown primary whose primary site could not be identified during the appropriate pretreatment evaluation. The patient was a 58 -yearold woman with a history of passive smoking and with no history of cancer in the family. Her current condition started with asthenia, adynamia, and pallor, followed by palpitations. An abdominopelvic computed tomography (CT) scan was performed, showing multiple osteolytic lesions distributed in all bone structures and axillary adenopathy on the left side. As part of the approach and given the high suspicion of multiple myeloma, tests were performed. The results were negative for multiple myeloma. A PET-CT scan was performed and showed left axillary adenopathy. The breasts and other organs were not affected. Left axillary lymph node resection revealed breast primary metastatic pleomorphic lobular carcinoma. Due to the metastatic disease (caused by the primary breast cancer), it was decided to start chemotherapy.




\section{Case Reports in Oncology}

\section{Background}

Cancer of unknown primary (CUP), also called "occult primary cancer," is defined as a set of malignant metastatic tumors confirmed by pathology, whose primary site cannot be identified during the appropriate pretreatment evaluation. CUP includes a metastatic cancer confirmed by the following: complete clinical history, physical examination, laboratory studies, imaging, and invasive procedures according to the presentation along with a pathological evaluation with hematoxylin and eosin stains and immunohistochemistry. The clinical presentation of this group of malignancies is diverse and they are characterized by having a poor prognosis, with a median survival rate of 6-9 months [1]. The primary site of the CUP is identified in less than $30 \%$ of the occasions and even in autopsies it can only be successfully identified in $20-50 \%$ of the cases. In the United States in 2011, there were 31,000 new cases of CUP, which accounted for $2 \%$ of all cancers in the same country. Both genders are affected equally, with a median age at presentation of 60 years. Unfortunately, there is a lack of specificity in the registry in terms of identifying the cause of death by CUP [2].

\section{Case Presentation}

We report the case of a 58-year-old woman with a history of passive smoking for 20 years, with no history of cancer in the family, a personal history of major depressive disorder treated with desvenlafaxine $37.5 \mathrm{mg}$ /day since 2012, and hypercholesterolemia treated with rosuvastatin $10 \mathrm{mg} /$ day since 2013. She had a surgical history of hemorrhoidectomy, hysterectomy due to uterine myomatosis, and cesarean section. Her current condition started in January 2015 with asthenia, adynamia, and pallor. In February of the same year, palpitations were added. She denied dyspnea or an anginal equivalent. She was referred to a hematologist who performed a blood count where microcytic hypochromic anemia was documented ( $\mathrm{Hb} 6 \mathrm{~g} / \mathrm{dL})$ compatible with iron deficiency, and intravenous iron treatment was started. Panendoscopy revealed grade B esophagitis, nodular gastropathy in the antrum and body, and bulb duodenitis with minimal bleeding. Colonoscopy was reported as normal. Gastric, duodenal and ileal biopsies were negative for malignancy. Complementary blood tests revealed high alkaline phosphatase levels of $154 \mathrm{U} / \mathrm{mL}$, so an abdominopelvic computed tomography (CT) scan was performed, finding multiple osteolytic and osteoblastic lesions distributed in all bone structures, unspecified lesions in both ovaries, hepatic cysts, bilateral urinary tract dilation and a 14-mm axillary adenopathy on the left side. Hospitalization was the next course of action.

\section{Discussion}

As part of the approach and given the high suspicion of multiple myeloma, the following tests were performed: bone marrow aspiration and biopsy, protein electrophoresis in serum and 24-h urine, and total serum immunoglobulins. The results were negative for multiple myeloma, and bone marrow biopsy showed poorly differentiated metastatic adenocarcinoma with ring cells (Fig. 1). The most common malignant bone tumor is metastatic carcinoma, the most common primary bone tumor is multiple myeloma, and the most common primary solid 


\section{Case Reports in Oncology}

Case Rep Oncol 2018;11:541-548

DOI: $10.1159 / 000491600$

(c) 2018 The Author(s). Published by S. Karger AG, Basel www.karger.com/cro

Dorantes-Heredia et al.: Searching for the Culprit: Metastases from a Cancer of Unknown Primary

bone tumor in adults is osteosarcoma [3]. It is hypothesized that the reason for the cancer to be a CUP is due to the fact that there was regression of the primary tumor after the metastases or that the primary is too small to be detected with the current imaging techniques. Other authors suggest that the primary tumor can no longer be elucidated since it was eliminated or contained by the immune system. Sometimes, years after the treatment of metastatic disease, the phenomenon of "appearance of the primary tumor" may occur and be evident even if the initial lesions of the CUP have disappeared [4]. The patterns of presentation may suggest a CUP, although it should be taken into account that these tumors can metastasize to any location. Therefore, the approach is quite complicated and should not be limited to the form of presentation. By light microscopy, 5 subtypes of CUP can be identified: moderate adenocarcinoma (well differentiated) (60\%), undifferentiated adenocarcinoma (29\%), squamous cell carcinoma (5\%), undifferentiated carcinoma (3\%), and neuroendocrine carcinoma (2\%) [5]. Immunohistochemistry helps in the approach of CUPs when they are poorly differentiated or undifferentiated tumors. These techniques are not specific or completely sensitive; they have not improved outcomes and should be guided by the available clinical information to avoid a broad panel of tests [6]. To support the immunohistochemical study in carcinomas, cytokeratins 7 and 20 can be used (Table 1); however, the expression of antibodies can change with the development of metastases [7, 8]. Therefore, a series of "organ-specific" markers should be completed to make a more precise diagnosis (Table 2) [9-11]. Due to the presence of the axillary ganglion, a digital mammography and bilateral ultrasound were performed, and the results were negative for malignancy. Pelvic ultrasound showed no alterations in both ovaries. PET-CT manages to identify between 27 and 57\% of the CUPs and the reported sensitivity is around $84 \%$. More prospective studies are needed in order to compare this modality versus traditional imaging studies, and to be able to measure the impact on the overall survival of patients [12]. The PET-CT scan showed lytic lesions with hypercaptation at the spine, pelvis, femur, right humerus, parietal and frontal bone, left axillary adenopathy, and left ovary. Breasts and other organs were not affected (Fig. 2). Left axillary lymph node resection revealed breast primary metastatic pleomorphic lobular carcinoma in 1 of 2 axillary lymph nodes. Estrogen receptors were positive in $90 \%$ of neoplastic cells, progesterone receptors were positive in 1\%, HER2 receptors were negative and Ki67 receptors were positive in $30 \%$ (Fig. 3). Due to the metastatic disease (caused by the primary breast cancer), it was decided to start palliative chemotherapy with paclitaxel $80 \mathrm{mg} / \mathrm{m}^{2}$ weekly for 12 weeks. The prognosis of patients with CUP is divided into two main groups, favorable and unfavorable. The first one includes: female gender and limited and potentially resectable metastatic disease. However, most of the patients belong to the unfavorable prognosis group: male gender, adenocarcinoma with metastasis to various organs, and central nervous system disease [13]. The chemotherapy that has mostly been used in patients with CUP is based on platinum and taxanes, specifically carboplatin plus paclitaxel. This scheme is the most experienced worldwide, and the number of cycles is determined by the tolerance and response to the treatment in each patient [14]. There are currently three commercial research studies of microarrays of 1,500 genes created from databases of 15 tumor tissues and 60 histological morphologies. The molecular study establishes a "result of similarity" on a scale of $0-100 \%$ for each of the 15 tumors. With a result of $\geq 30 \%$ it is "tissue of probable origin," $5-29 \%$ is "undetermined," and $<5 \%$ is "not similar." In 2008, the FDA approved its use for the study of unknown primary tumors [15]. The international guidelines recommend that until more evidence exists, the routine use of 
molecular profiles should be restricted only to those patients in whom the pathological evaluation inclines only towards the carcinoma spectrum. This new technology is promising; it only requires small tissue samples and immunohistochemistry to complement it. The impact on global survival is currently unknown given the difficulty of diagnosis, which requires highly specialized equipment and personnel, as well as 2 weeks for a final report. There are no direct comparisons between each of the available kits [2].

\section{Conclusion}

CUP is one of the main problems in medical oncology due to its complex diagnosis and therefore the delay of treatment. The presentation patterns of the CUP are of great importance because they can suggest the location of the same, although due to its metastatic spread to any location, the approach is quite complicated. As of today, diagnostic techniques are not very specific and sensitive, so the diagnosis must be guided by the clinical features to avoid the use of unnecessary tests. The prognosis of patients with CUP relies on multiple factors; therefore, early diagnosis and initiation of therapy is of vital importance.

\section{Statement of Ethics}

Informed consent was gained from the patient for publication of this case report and the accompanying images.

\section{Disclosure Statement}

The authors deny any conflict of interest.

\section{References}

1 Hemminki K, Bevier M, Hemminki A, Sundquist J. Survival in cancer of unknown primary site: populationbased analysis by site and histology. Ann Oncol. 2012 Jul;23(7):1854-63.

2 National Comprehensive Cancer Network. Occult primary (version 1.2015) 2015 [cited 2015 Mar 20]. Available from: http://www.nccn.org/professionals/physician_gls/pdf/occult.pdf.

3 Siegel RL, Miller KD, Jemal A. Cancer statistics, 2015. CA Cancer J Clin. 2015 Jan-Feb;65(1):5-29.

4 Varadhachary GR, Raber MN. Cancer of unknown primary site. N Engl J Med. 2014 Aug;371(8):757-65.

5 Schwartz AM, Harpaz N. A primary approach to cancers of unknown primary. J Natl Cancer Inst. 2013 Jun;105(11):759-61.

6 Park SY, Kim BH, Kim JH, Lee S, Kang GH. Panels of immunohistochemical markers help determine primary sites of metastatic adenocarcinoma. Arch Pathol Lab Med. 2007 Oct;131(10):1561-7.

7 Fisher C. Immunohistochemistry in diagnosis of soft tissue tumours. Histopathology. 2011 Jun;58(7):100112.

8 Chu PG, Weiss LM. Keratin expression in human tissues and neoplasms. Histopathology. 2002 May;40(5):403-39.

9 Rubin BP, Skarin AT, Pisick E, Rizk M, Salgia R. Use of cytokeratins 7 and 20 in determining the origin of metastatic carcinoma of unknown primary, with special emphasis on lung cancer. Eur J Cancer Prev. 2001 Feb;10(1):77-82. https://doi.org/10.1097/00008469-200102000-00009. 


\section{Case Reports in Oncology}

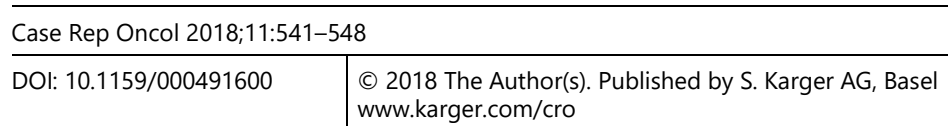

Dorantes-Heredia et al.: Searching for the Culprit: Metastases from a Cancer of Unknown Primary

10 Tot T. Cytokeratins 20 and 7 as biomarkers: usefulness in discriminating primary from metastatic adenocarcinoma. Eur J Cancer. 2002 Apr;38(6):758-63.

11 Chu P, Wu E, Weiss LM. Cytokeratin 7 and cytokeratin 20 expression in epithelial neoplasms: a survey of 435 cases. Mod Pathol. 2000 Sep;13(9):962-72.

12 Kwee TC, Kwee RM. Combined FDG-PET/CT for the detection of unknown primary tumors: systematic review and meta-analysis. Eur Radiol. 2009 Mar;19(3):731-44.

13 Ariza A, Balana C, Concha A, Hitt R, Homet B, Matilla A, Alba E. Update on the diagnosis of cancer of unknown primary (CUP) origin. Clin Transl Oncol. 2011 Jul;13(7):434-41.

14 Greco FA, Lennington WJ, Spigel DR, Hainsworth JD. Molecular profiling diagnosis in unknown primary cancer: accuracy and ability to complement standard pathology. J Natl Cancer Inst. 2013 Jun;105(11):78290.

15 Meiri E, Mueller WC, Rosenwald S, Zepeniuk M, Klinke E, Edmonston TB, et al. A second-generation microRNA-based assay for diagnosing tumor tissue origin. Oncologist. 2012;17(6):801-12.

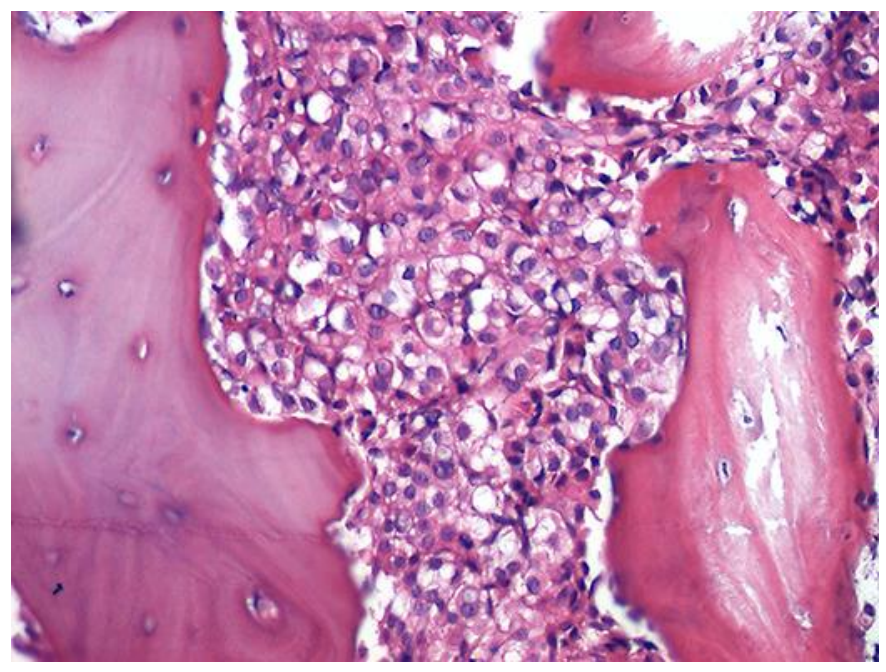

Fig. 1. Bone marrow biopsy (hematoxylin and eosin stain) that shows bone trabeculae and medullary space with diffuse infiltration by a malignant epithelial neoplasm with a pattern of solid growth constituted by large cells, with an inconspicuous nucleolus and a vacuolated cytoplasm. Some of the cells have the nucleus rejected to the periphery. It was interpreted as a poorly differentiated adenocarcinoma. $\times 40$ (from Rita Dorantes-Heredia). 


\section{Case Reports in Oncology}

\begin{tabular}{l|l}
\hline Case Rep Oncol 2018;11:541-548 \\
\hline DOI: 10.1159/000491600 & $\begin{array}{l}\text { (c) } 2018 \text { The Author(s). Published by S. Karger AG, Basel } \\
\text { www.karger.com/cro }\end{array}$
\end{tabular}

Dorantes-Heredia et al.: Searching for the Culprit: Metastases from a Cancer of Unknown Primary
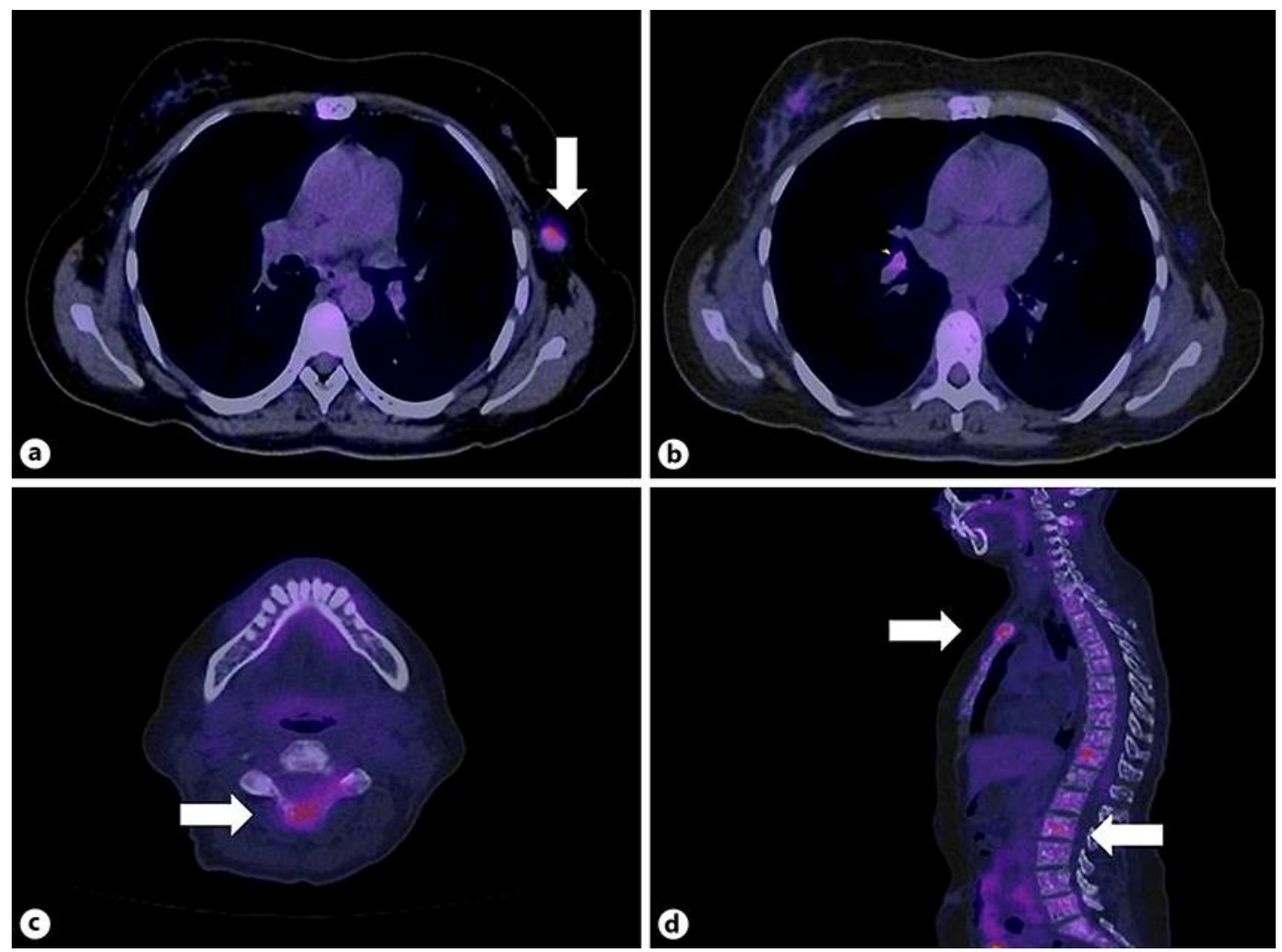

Fig. 2. PET-CT with 18-fluorodeoxyglucose. a Axial thoracic section that shows hyperuptake in the left axillary ganglion without other hyperuptake sites. $\mathbf{b}$ There was no uptake at the level of breast glands or other sites at this section. c Osteoblastic lesions were found at the cervical level number 4. d Hypercaptation appreciated in osteolytic and blastic lesions in vertebral bodies at various levels of the dorsal and lumbar spine and sternum. 


\section{Case Reports in Oncology}

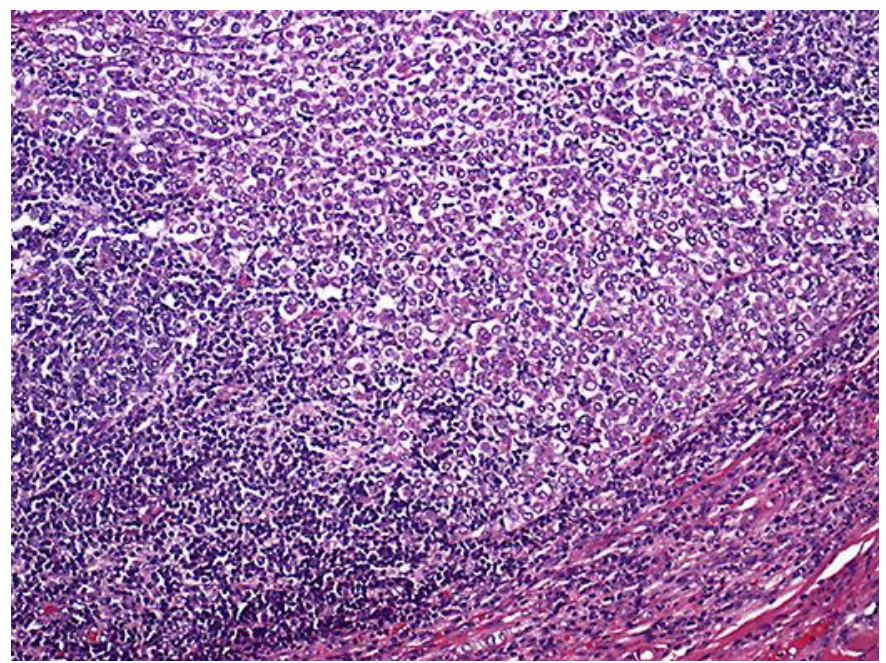

Fig. 3. Lymph node (hematoxylin and eosin stain) that shows diffuse infiltration by a poorly differentiated malignant epithelial neoplasm, with a solid growth pattern constituted by large cells with small nucleolus and moderate vacuolated eosinophilic cytoplasm. Many of the cells have the nucleus rejected to the periphery. The morphology is compatible with breast primary pleomorphic lobular carcinoma. $\times 40$ (from Rita Dorantes-Heredia).

Table 1. Immunoprofile of cytokeratins (CK) 7 and 20 in neoplasms

\begin{tabular}{ll}
\hline CK7+/CK20+ & Urothelial carcinoma \\
& Pancreatic carcinoma \\
& Mucinous ovarian carcinoma \\
\hline CK7+/CK20- & Non-small cell lung cancer and small cell lung cancer \\
& Breast carcinoma \\
& Non-mucinous ovarian cancer \\
& Endometrial adenocarcinoma \\
& Mesothelioma \\
& Epidermoid carcinoma of the cervix \\
\hline CK7-/CK20+ & Colorectal adenocarcinoma \\
& Merkel cell carcinoma \\
\hline CK7-/CK20- & Pulmonary epidermoid carcinoma \\
& Prostate adenocarcinoma \\
& Renal cell carcinoma \\
& Hepatocellular carcinoma \\
& Adrenal carcinoma \\
& Thymic carcinoma
\end{tabular}


Table 2. Antibodies used in organ-specific immunohistochemistry

\begin{tabular}{|c|c|c|}
\hline Antibody & Commonly used to identify & Can also be expressed in \\
\hline TTF-1 & Pulmonary adenocarcinoma & Thyroid carcinoma \\
\hline CDX2 & Carcinoma of gastrointestinal tract & $\begin{array}{l}\text { Carcinomas of the pancreato-biliary tract } \\
\text { Bladder carcinomas } \\
\text { Carcinomas of the intestinal type of ovary or lung }\end{array}$ \\
\hline $\mathrm{RE} / \mathrm{RP}$ & $\begin{array}{l}\text { Breast carcinoma } \\
\text { Endometrial carcinoma }\end{array}$ & $\begin{array}{l}\text { Ovarian and lung carcinomas } \\
\text { Neuroendocrine tumors }\end{array}$ \\
\hline CA-125 & Ovarian tumors & $\begin{array}{l}\text { Mesothelioma } \\
\text { Pancreatic, hepatic, and biliary carcinomas } \\
\text { Bladder adenocarcinoma } \\
\text { Endocervical adenocarcinoma }\end{array}$ \\
\hline PSA & Prostate tumors & $\begin{array}{l}\text { Salivary gland tumors } \\
\text { Breast tumors }\end{array}$ \\
\hline Hep par-1 & Hepatocellular carcinoma & Gastric carcinoma \\
\hline Thyroglobulin & Follicular thyroid carcinoma & - \\
\hline RCC & $\begin{array}{l}\text { Renal clear cell carcinoma } \\
\text { Papillary renal cell carcinoma }\end{array}$ & $\begin{array}{l}\text { Yolk sac tumor } \\
\text { Embryonal carcinoma } \\
\text { Mesothelioma }\end{array}$ \\
\hline ACE & $\begin{array}{l}\text { Lung, colon, stomach, bladder, } \\
\text { endocervix, breast carcinomas, and } \\
\text { chordomas }\end{array}$ & - \\
\hline EMA & $\begin{array}{l}\text { Synovial sarcoma } \\
\text { Synovial epithelium sarcoma } \\
\text { Meningioma } \\
\text { Choroid plexus carcinoma } \\
\text { Chordoma } \\
\text { Ependymoma }\end{array}$ & - \\
\hline WT1 & Wilms tumor & $\begin{array}{l}\text { Mesothelioma } \\
\text { Serous ovarian carcinoma } \\
\text { Desmoplastic small round cell tumor }\end{array}$ \\
\hline HMB45 & Melanoma & $\begin{array}{l}\text { Smooth muscle tumor } \\
\text { Perivascular epithelioid cell tumor } \\
\text { Clear cell sarcoma } \\
\text { Low-grade endometrial stromal sarcoma }\end{array}$ \\
\hline Melan-A & Melanoma & $\begin{array}{l}\text { Adrenal tumor } \\
\text { Perivascular epithelioid cell tumor } \\
\text { Clear cell sarcoma }\end{array}$ \\
\hline $\begin{array}{l}\text { Chromogranin, } \\
\text { synaptophysin, } \\
\text { CD56 }\end{array}$ & Neuroendocrine tumors & $\begin{array}{l}\text { Ewing's sarcoma/primitive neuroectodermal tumor } \\
\text { Paragangliomas } \\
\text { Medullary thyroid carcinoma }\end{array}$ \\
\hline
\end{tabular}

